Can parents' homework assigned compensate for disadvantaged students' learning achievement in Mainland China?

\author{
Zhao, Ningning $\square$ \\ Beijing Normal University, China (tintinning@ hotmail.com) \\ Valcke, Martin \\ Ghent University, Belgium (Martin.valcke@ugent.be) \\ Desoete, Annemie \\ Ghent University, Belgium (annemie.desoete@telenet.be) \\ Verhaeghe, Jean Pierre \\ Ghent University, Belgium (jphcv@yahoo.com)
}

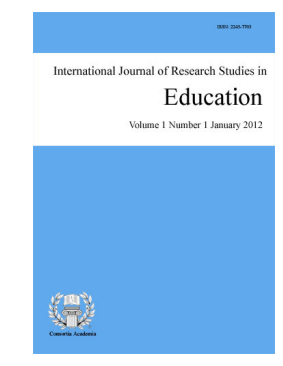

ISSN: 2243-7703 Online ISSN: 2243-7711

OPEN ACCESS

\title{
Abstract
}

Homework aims to improve variables and processes related to academic achievement. In China, homework assignments are not only given by teachers, but also by parents and students themselves. In present study we focus on the impact of additional homework developed by parents and learners. The data comes from 10,959 students enrolled in Chinese primary schools. The results reveal that parents and students from disadvantaged families approach homework as a way to compensate for an unprivileged background. Students develop homework assignments depending on the extent to which their parents develop homework. It shows that the learning performance of students improves significantly when their parents with low level jobs assign a moderate level of homework. In contrast, student achievement is significantly lower when their parents with high level jobs don't assign any homework. Students from disadvantaged families benefit largely from homework involvement. Although there is a certain compensatory impact of homework, educational authorities should provide additional support to students from disadvantaged families.

Keywords: homework; primary school; socioeconomic status 


\section{Can parents' homework assigned compensate for disadvantaged students' learning achievement in Mainland China?}

\section{Introduction}

It is revealed that particularities of the Chinese cultural context incorporate the U-shape relationship between the socio-economic status (SES) and learning achievement (Zhao, Valcke, Desoete, \& Verhaeghe, 2012). Students from lowest SES family have the opportunity to get the higher achievement compared to their peers from the family with higher SES (Zhao et al., 2012). Since high quality education resource is rare in China (Wang, 2004), students' effort is regarded as the approach to the success (Li, 2003). Recently, homework is stressed as an engagement indicator, referring to the level of motivation, expectancies, efforts and self-regulation (Hong, Peng, \& Rowell, 2009; Zimmerman \& Kitsantas, 2005; Warton, 1997). Parents and teachers believe that homework accelerates knowledge acquisition and academic achievement (Cooper, Robinson, \& Patall, 2006). Chinese people highlight homework engagement for the high achievement and actual homework time requirement are very high in practice (Guo, Liu, \& Zhao, 2006). Thus, the Ministry Of Education (MOE, 1994) required: "reduce too heavy homework assignments for primary and secondary school students" (no homework time for grade 1, less than 30 minutes for grade 2-3, less than 45 minutes for grade 4 and less than 60 minutes for grade 5-6).

Less research on homework is available focusing on the Chinese context for primary schools. In this study, homework which was related to the persons' effort and self-regulation skill was selected as one of the mediators for SES and achievement. Does homework engagement work for achievement in China? Besides the teachers' homework, how do the parents and students with different SES background assign homework to improve the achievement? How do the parents and students in low quality school assign homework to improve the achievement? And do these efforts on homework improve the achievement? This might result in a more complex picture of the relationship between school and family related variables and processes that affect the impact of types of homework on achievement.

\section{Literature Review}

\subsection{Measurement of time on Homework}

Homework can be defined as the tasks assigned to students by school teachers that is meant to be performed during non-school hours (Cooper, 1989). A meta-analysis of previous research, set up in the period 1987-2003 yields inconsistent results (Cooper, Robinson, \& Patall, 2006). Some studies observe a positive effect of homework on academic achievement (Trautwein, 2007), others claim that there are no differences in student achievement as a function of time spent on homework (Buell, 2004) and still others found a negative relationship between the workload of homework and attitude on achievement of pupils (Bennett \& Kalish, 2006).

In different cultures, homework can be approached differently. In most of western countries, studies mainly focus on homework assigned by school teachers. In Asian countries, homework is not only assigned by the teacher, but often also by the parents and the students themselves (Ebbeck, 1996; Guo, Liu, \& Zhao, 2007). Parental homework involvement as well as the students' engagement in homework can be expected to be an important moderator in the relationship between socio-economic status and academic achievement (Ebbeck, 1996). In the present paper, we focus in particular on the alternative approaches towards homework time that is elaborated by parents and/or students.

Homework has been measured in various ways (Cooper, Robinson, \& Patall, 2006). Mainly, three measures 
are adopted to determine whether and how much time students spend on their homework. First, some researchers ask the person assigning homework how long the homework should take. Second, one asks these persons how much time students actually spend on their homework. Thirdly, students are asked to report about the time spent in working on homework. The latter self-reported measures appear to be less reliable (Hallam, 2004) because the learners' perception of time might be less accurate as compared to adults. In addition, the experienced workload can bias these self-reported measures. Findings about the relationship between homework and academic achievement vary on the basis of how homework is measured (Cooper, Robinson, \& Patall, 2006).

\subsection{Toward an integrated model}

As mentioned in the previous section, relationship between characteristics of school and family, efforts of parents and students on homework and students' achievement are complex. Considering the available research evidence, we can develop an integrated model that interlinks these variables (Fig 1). For ease of interpretation, linkages between variables are identified between brackets. The hypothetical relationships between the variables build on a variety of theoretical and empirical data:

\subsubsection{Impact of characteristics of school and family on the homework involvement}

Effect of school urbanization and family SES on parents' homework involvement - It is known that parents' involvement in homework does not only vary with parents' SES, but also depends on the school context (Cooper, Lindsay, \& Nye, 2000; Grolnick, Benjet, Kurowski, \& Apostoleris, 1997; Kerbow \& Bernhardt, 1993). On the one hand, characteristics of school, including nature setting of school (urban, rural), size and type, influence the parents' behavior (Shouse, 1996). Parents of the students enrolled in schools in rural areas, report less learning involvement as compared to parents of children in urban or sub-urban schools (Prater, Bermudez, \& Owens, 1997; Mulntire, Marion, \& Quaglia, 1990). It is because parents who have the similar beliefs as teachers' were found to be more highly involved in homework as compared to other parents (Bourdieu, 1977; Bowles \& Gintis, 1976). On the other hand, previous studies reveal that parents in poorer families give less support to the development of their children's autonomy (Cooper, Lindsay, \& Nye, 2000). Some studies demonstrate these parents to have more difficulties getting involved in students' learning (Scott-Jones, 1984).

Effect of school urbanization, family SES and parents' homework involvement on students' self-assigned homework - Firstly, special characteristics of the schools seem to affect the way students are involved in homework (Lee \& Bryk, 1989). For example, a Catholic school with a strong emphasis on academic achievement reinforces students' active participation in homework (Bryk, Holland, Lee, \& Carriedo, 1984). However, when school achievement is not of central student value, involvement in homework is less probable (Maehr \& Nicholls, 1980).

Secondly, it is not surprising that parents' socioeconomic status influences students' engagement in homework (Chiu \& Zeng, 2008). The students from families with a lower SES have access to fewer educational resources and reflect a lower academic motivation (Hampden-Thompson \& Johnston, 2006). The relationship between SES and students' effort and perseverance seems to be stronger in richer countries as compared to poor countries implying the stronger resources effect (Chiu \& Zeng, 2008).

Thirdly, studies reveal a positive correlation between parental and student attitudes towards homework (Cooper, Lindsay, \& Greathouse, 1998). Parental beliefs and behavior linked to academic achievement seem to be learned by children (Eccles, 2007). And the students have more opportunity to report autonomously self-regulation learning while their parents provide autonomy support (Grolnick, Wendy, \& Ryan, 1989).

2.2.2 Impact of interaction of characteristics of school, family SES, parent's homework involvement and students' self-assigned homework on academic achievement

Relations between school urbanization, family SES, parents' involvement on homework and students' 
achievement - In general, the previous studies reveal that the parents' involvement in homework have a positive effect on the students' achievement (Fan \& Chen, 2001; Hoover-Dempsey, Battiato, Walker, Reed, DeJong, \& Jones, 2001; Jeynes, 2003; Xu \& Corno, 1998). But, if we consider the situation of school, family SES, what is the result? On the one hand, in China, the urbanization level of schools affects the students' achievement and rural schools have a lower educational quality (Gordon \& Wang, 2000). It shows that the students from school in the rural side achieve lower than the students in the urban. There is an interaction effect of the characteristic of school and family SES on the students' achievement (Zhao et al., 2012). And Ma (2000) argues that school situation and parental involvement significantly affect the relationship between mathematics achievement and individual SES. On the other hand, parental involvement seems to interact with the relationship between SES and student achievement. Characteristics of family SES have been known to be related to academic achievement (Sirin, 2005; White, 1982). Though it is a consistent finding that learners in a disadvantaged situation are at risk of attaining lower achievement levels, there is also the positive finding that parental involvement in children's homework will affect these disadvantaged children's academic success (Englund, Luckner, Whaley, \& Egeland, 2004; Fan \& Chen, 2001; Ho \& Willms, 1996). And, more positive parent involvement was associated with lower test scores and lower class grades, especially for elementary school students (Cooper, Lindsay, \& Nye, 2000). Here, the parental involvement on homework as an effort engagement influences the effect of characteristics of school and family SES on students' achievement.

Relations between school urbanization, family SES, students' self-assigned homework and students' achievement - The meta-analysis study on homework shows, the students' engagement in the homework improves the students' achievement (Cooper, Robinson, \& Patall, 2006). And in USA, some study on the disadvantaged students in the disadvantaged school reveals that, to spend more time on homework is more important for African American students $(b=.370)$ than it is for white students $(b=.147)$ (Bankston III, \& Caldas, 1993). It implies that there might be 4-ways interaction for the students' achievement.

In sum, the available research is clear about direct relationships between homework and achievement and the potential impact of parent and school characteristics. But there is hardly evidence about the complex interplay between all the variables involved. In addition no research is available set up in the Chinese setting and focusing on the nature and impact of teacher and student assigned homework. This brings us to the focus of the present study.

\section{Methodology}

\subsection{Research questions}

Building on the introductory part of this study, the present study focuses on the following key research questions. Firstly, to what extent do parents assign homework? And how is this affected by parent and school characteristics? Secondly, to what extent do students assign homework? And how is this affected by parents' assignment of homework, and parent and school characteristics? Thirdly, we question the impact of parent and student engagement in homework on achievement and how this relationship is affected by school and parent related characteristics.

For the hypothetical model, five variables were linked together to develop a conceptual model. Students' mathematics achievement level (A) is adopted as the single dependent variable. In total four variables are expected to influence mathematics achievement: urbanization level of the region of the school (U), parents' job level $(\mathrm{J})$, the extent to which parents assign homework $(\mathrm{P})$ and the extent to which the students assign homework to themselves $(\mathrm{S})$.

\subsection{Sample}

The data used in the present study are derived from a large scale study focusing on mathematics 
achievement in Chinese primary schools (Zhao et al., 2012). The data were obtained from pupils enrolled in one 20 schools, geographically positioned in five provinces or cities with a varying level of Gross Domestic Product (GDP). The sample was representative with respect to developmental level and level of urbanization, including Shizuishan city in NingXia Province from Western of China, Handan city in Hebei Province from middle of China, Weifang city in Shandong Province from Eastern of China, Tianjing City (this city level is equal to Province) from Northern of China, Guangzhou city in Guandong Province from Southern of China. In total, 10,959 students from Grade 1 to Grade 6 participated in the study, of which $51.88 \%$ were male. Table 1 represents basic sample characteristics.

Table 1

Description of Sampling

\begin{tabular}{|c|c|c|c|c|}
\hline & Low level job & Blue collar & White collar & Total \\
\hline Rural school & 852 & 999 & 176 & 2027 \\
\hline Rural-Urban school & 1180 & 2070 & 743 & 3993 \\
\hline Urban school & 702 & 2446 & 1791 & 4939 \\
\hline Total & 2734 & 5515 & 2710 & 10959 \\
\hline
\end{tabular}

\subsection{Research measures}

Student mathematics achievement level - All students were tested as to the mastery of three mathematics domains, reflected in the most recent Chinese curriculum standards in China (MOE, 2001): number and algebra, shape and space, statistics and probability. And, the test covered a range of mathematical building blocks: number reading skills, mathematical lexicon, knowledge, procedural knowledge, linguistic skills, mental representation, contextual skills, selecting relevant information, number sense skill, memory skills, visualization or mental representation skills and logical thinking (Desoete \& Roeyers, 2005; Nunes et al., 2007; Zimmermann $\&$ Cunningham, 1991). The homogeneous of the test was attained by the Item Response Theory. During the IRT analysis, all of the items which cannot be convergence into the model were deleted. The internal consistency (Cronbach's $\alpha$ ) of the tests, at each grade, ranged from 0.93 to 0.96 (Zhao, Valcke, Desoete, Verhaeghe, \& Xu, 2011). And the students from grade 1 to grade 6 got continuum scores. But in view of the present study, on the base of their mathematics achievement score in each grade, students were categorized in one of three achievement levels in each grade: low achiever (lower 25\%), average achiever (middle 50\%) and high achievers (higher $25 \%$ ).

School characteristic: Level of urbanization - Schools are categorized based on the level of GDP and urbanization level. Three categories were distinguished: rural schools (schools in a region with a low urbanization level and low GDP), rural-urban schools (schools in a region with an average urbanization and GDP-level), urban schools (schools in a region with a high urbanization and GDP-level). The potential impact of the urbanization level of a school's region cannot be underestimated. Urban schools are expected to have more available resources, better qualified teachers, a stronger impact of school policies and school leadership.

Level of parents'job - Father and mother's job was collected by the support of the school. If the school does not have the information on parents' job, a questionnaire with the homework was given to the students which would be finished supported by parents. Father and mother's' jobs were initially coded according to one of the 27 hierarchical levels of $\mathrm{Li}(2005 \mathrm{a} ; 2005 \mathrm{~b})$. In view of the present study, the father and mother's job with 27 levels each were carried out by applying the WLSM method for the factor analysis (Mplus 5.1). And the final factor scores are record by 25\%, 25-75\% and 75-100\% categories: low job level (unschooled manual labor jobs), blue collar level (schooled manual labor jobs) and white collar job level.

Homework assignment - The students answered the questionnaire supported by their parents. In the original study, questions focused on homework assignment by the teacher, the parents or the student themselves. 
$>$ Does your mathematics teacher assign the homework for you? If yes, how many minutes do you spend on it?

$>$ Do your parents assign the math homework for you except the teachers' homework? If yes, how many minutes do you spend on it?

$>$ Do you assign the math homework for yourself except the parents' and teachers' homework? If yes, how many minutes do you spend on it?

For the first set of questions, up to $95 \%$ of the students replied that they received homework from their teachers which will be spent less than 30 minutes to finish. Homework, assigned by the teacher, was not incorporated in the conceptual and research models.

For the other set of questions, based on the Chinese situation reported in the literature review, the answers were divided into three groups for being assigned none, short homework $(=$ or $<$ than 30 minutes) or longer homework (> 30 minutes) by their parents $(\mathrm{P})$ or by themselves (S). Given the focus of the present study, these two variables and values were used to carry out the analyses.

\subsection{Data analysis}

Considering the complexity of the conceptual model in which - next to direct relationships between variables - also a large number of interaction effects can be defined, a specific analysis approach was adopted. Models were designed and evaluated in view of looking for the most parsimonious model. To evaluate the goodness of the fit of the consecutive models, likelihood ratio chi-square (L2) and Akaike's information criteria (AIC) and (BIC) were calculated with the LEMWIN package (Vermunt, 1997), a prerelease version of Latent Gold 5 (Vermunt \& Magidson, 2007), and Mplus Version 5 (Muthen \& Muthen, 1998-2007). Based on the previous study's results that there was interaction effect of school and family on achievement (Zhao et al., 2012), The model selection processes started from the most complex full model incorporating 5 -way interaction effects of mathematics achievement level (A), urbanization level of the region of the school (U), parents' job level (J), the extent to which parents present homework $(\mathrm{P})$ and the extent to which the students assign homework to themselves (S).

Generally, the M0 and M1 are said to be the nested model if all of the effect in M1 are subset of the value contained in M0. The difference between the L2 between M0 and M1 is the test whether deleting some interactions causes the model become significantly worse as compared to the previous model. All of the information about the model selection can be asked for the authors if needed.

\section{Results}

\subsection{Model selection}

As stated above, the model selection procedure started with the most complex model. Tables, documenting the consecutive steps in the model testing procedure, can be obtained from the corresponding author. The procedure aimed at looking for the most parsimonious model, but still achieving a good fit between the theoretical model and the model reflected in the data. The final model (model 13) reflects the best fit, leaving out the impact of particular variables without losing significant information. The model represents an AIC value of -89.63 and BIC value of -819.83 , being the lowest values tested. Building on this model (See Figure 1), three different logit models will be tested in the following sections of this article: (1) P । UJ \{UP\}; (2) S I UJP \{UPS, UJS\}; and (3) A I UPSJ \{UJSA, UPJA\}. The following equations were applied to test the relationships in the model 13: 
$\log \mathrm{P}_{\mathrm{ji}}=\mu+\lambda_{\mathrm{H}}^{\mathrm{u}}+\lambda_{\mathrm{j}}^{\mathrm{j}}+\lambda_{\mathrm{ij}}^{\mathrm{uj}}$

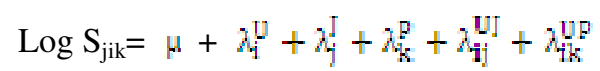

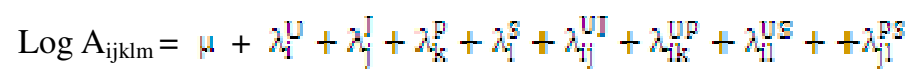

$$
+\lambda_{\mathrm{ijk}}^{\mathrm{UIP}}+\lambda_{\mathrm{ijl}}^{\mathrm{UIS}}
$$

[Model PIUJ]

[Model SIUJP]

Note: A-Mathematics achievement level; U-Urbanization level of the region of the school; J- parents' job level; P-The extent to which parents present homework; S-The extent to which the students assign homework to themselves.

To test the three logit models, Kaufman and Schervish method was further used to analyze the findings. For each categorical variable, the first category was used as the reference category to compare the logit equations (e.g., for variable $\mathrm{J}$, the lowest job level was used as a reference category). Then, the odd ratios of the logit equations were determined by calculating the natural log. For instance, given a Lambda value of .07 (expected value), the natural $\log$ is calculated $(=1.6032)$, implying that the odds of observing a particular value is 1.62 times higher than the value in the reference category. Detailed tables, reporting all the logit equation results and odds ratios, can be obtained from the author. In the next sections only summary information will be reported and some exemplary tables.

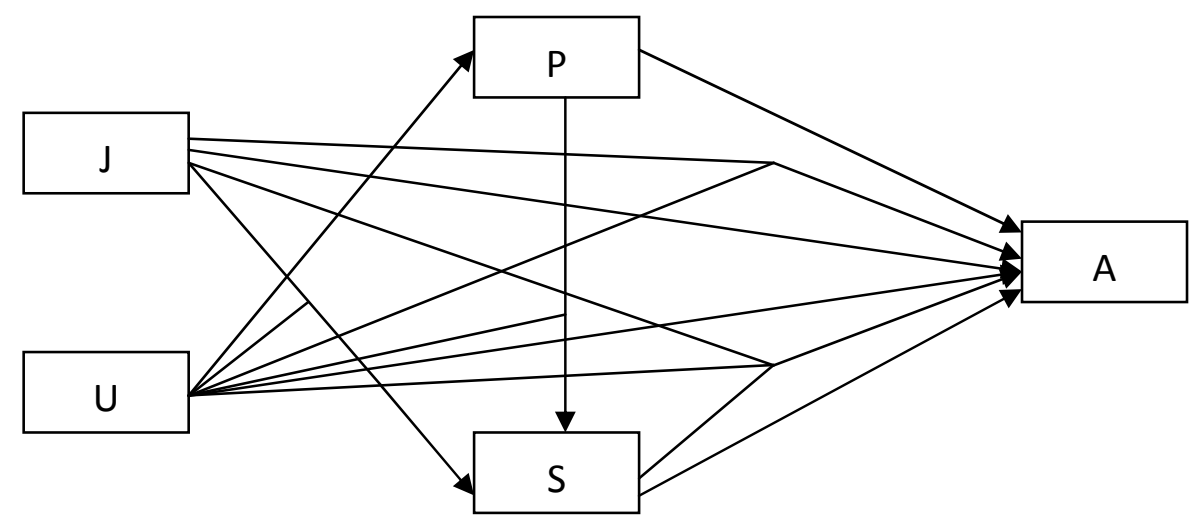

Figure 1. Final path model, resulting from the loglinear analysis

Note: Dependent variable: academic achievement (A);

Independent variables: Urbanization level of school region (U), level of homework assignment by parents (P), level of student homework assignment (S), and parents' job level (J).

\subsection{Parents' and student's homework}

4.2.1 To what extent do parents assign homework to students? What other variables in the model affect the level of homework assignment by parents?

In general, parents seldom assign homework to their students. The odds ratio of parents who don't assign homework to their children is 1.6 times larger than expected on the basis of the overall effect $(\exp (.07)=1.6032)$. Parents also seldom assign homework that lasts more than 30 minutes homework. The odds ratio of parents assigning longer homework is 1.03 less than expected on the basis of the overall effect $(\exp (-.03)=.97=1 / 1.03)$.

Does the urbanization level of the school (U) affect the extent to which parents assign homework? First, compared to rural schools (reference category), the odds that parents in rural-urban schools assign long 
Zhao, N.-N., Valcke, M., Desoete, A., \& Verhaeghe, J. P.

homework versus parents who give no homework is.02 (=1.02-1). In urban schools, the odds that parents give long homework increases up to $.38(=1.38-1)$ times more as compared to parents in rural schools. The odds that parents give short homework (between 0 to 30 minutes homework), is $.14(=1.14-1)$ higher in rural-urban schools as compared to rural schools. This also increases in urban schools where the odds is $.21(=1.21-1)$ higher as compared to rural schools.

4.2.2 Does assignment of homework by parents affect student's assignment of homework? And is this affected by the urbanization level of the school?

An example of the impact of urbanization levels (U) and parents' job level (J) on the students' level of homework assignment (S) is shown in Table 2. Student homework assignment varies by the urbanization level of the school and the job level of the parents.

\section{Table 2}

Logit equation for the odds of students' long homework vs. no homework, considering the school's urbanization and parents' job level

\begin{tabular}{|c|c|c|c|c|c|c|c|c|c|}
\hline /Parents & $\begin{array}{c}\text { Low } \\
\text { level } \\
\text { job }\end{array}$ & Blue & White & $\begin{array}{c}\text { Low } \\
\text { level } \\
\text { job }\end{array}$ & Blue & White & $\begin{array}{c}\text { Low } \\
\text { level } \\
\text { job }\end{array}$ & Blue & White \\
\hline & Logit & & Equation & Logit & & Difference & Odds & & ratio \\
\hline \multirow[t]{3}{*}{ Rural school } & .23 & -.23 & 0 & & & & & & \\
\hline & -.02 & -.02 & -.02 & .52 & -.43 & -.12 & & & \\
\hline & .31 & -.18 & -.1 & 0 & -.95 & -.64 & $1^{\mathrm{a}}$ & .39 & .53 \\
\hline \multirow[t]{3}{*}{ rural-urban school } & .23 & -.23 & 0 & & & & & & \\
\hline & .2 & .2 & .2 & .14 & .02 & .44 & & & \\
\hline & -.29 & .05 & .24 & -.38 & -.5 & -.08 & .68 & .61 & .92 \\
\hline \multirow[t]{3}{*}{ Urban school } & .23 & -.23 & 0 & & & & & & \\
\hline & -.18 & -.18 & -.18 & .05 & -.26 & -.33 & & & \\
\hline & 0 & .15 & -.15 & -.47 & -.78 & -.85 & .63 & .46 & .43 \\
\hline
\end{tabular}

The odds that students assign "long" homework to themselves (taking more than 30 minutes to tackle), is larger in students of parents with low level jobs and enrolled in rural schools. In table 2, the odds ratio is consistently lower than the reference category for students enrolled in rural-urban or urban schools and for students whose parents have a blue collar or white collar job. For instance the odds ratio that students assign long homework to themselves when their parents have a blue collar job and when they are enrolled in an urban school, is 2.17 times smaller $(2.17=1 / .46)$.

The odds that students assign "short" homework to themselves (requiring up to 30 minutes time to carry out) is higher in rural and urban schools when the parents job level is low or a blue collar job. In rural-urban schools, especially students with white collar parents assign short homework to themselves. The odds ratio is .39 times higher as compared to students with low job parents in rural schools $(.39=1.39-1)$.

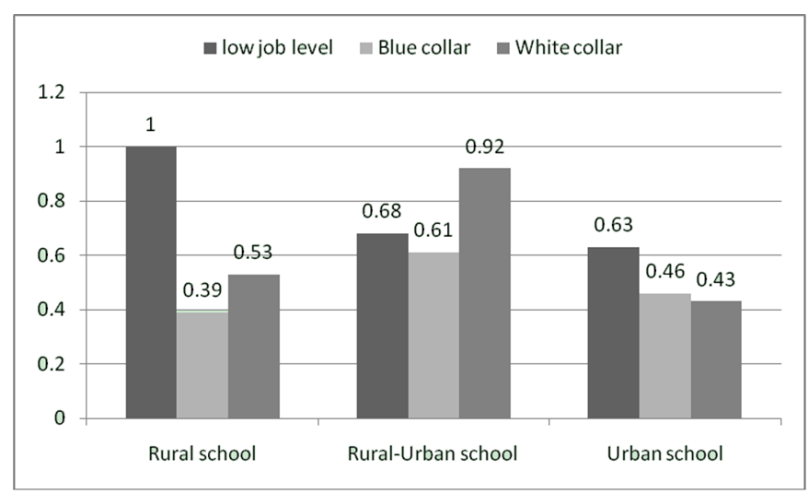

Figure 2. Final path model, resulting from the loglinear analysis 
4.2.3 Does assignment of homework by parents affect student's assignment of homework? And is this affected by the urbanization level of the school?

There is a clear relationship between parents' homework assignment on students' level of homework assignment. This is exemplified by the analysis results reported in Table 3 that focuses on the odds ratio that students assign "short" homework to themselves, depending on the level of homework assigned by their parents. Compared to the reference category of parents assigning no homework to students enrolled in rural schools, the odds that students assign short homework to themselves is clearly larger when also parents assign short homework to them. For instance, these odds are .43 times higher when parents assign short homework to learners enrolled in rural schools, $(.43=1.43-1) ; .20$ times higher when they are enrolled in rural-urban schools $(.20=1.39-1.19)$, but only .02 times higher when students are enrolled in urban schools $(.02=.96-.94)$.

Table 3

Logit equation for the odds of students' short homework vs. no homework, depending on parents' homework assignment and the school's urbanization.

\begin{tabular}{|c|c|c|c|c|c|c|c|c|c|}
\hline \multirow[t]{2}{*}{ School /Parents homework } & no & $0-30$ & $>30$ & no & $0-30$ & $>30$ & no & $0-30$ & $>30$ \\
\hline & Logit & & Equation & Logit & & Difference & Odds & & ratio \\
\hline \multirow[t]{3}{*}{ Rural school } & .05 & .23 & -.28 & & & & & & \\
\hline & -.07 & -.07 & -.07 & -.05 & .31 & -.46 & & & \\
\hline & -.03 & .15 & -.11 & 0 & .36 & -.41 & 1 & 1.43 & .66 \\
\hline \multirow[t]{3}{*}{ Rural-Urban school } & .05 & .23 & -.28 & & & & & & \\
\hline & .06 & .06 & .06 & .12 & .28 & -.22 & & & \\
\hline & .01 & -.01 & 0 & .17 & .33 & -.17 & 1.19 & 1.39 & .84 \\
\hline \multirow[t]{3}{*}{ Urban school } & .05 & .23 & -.28 & & & & & & \\
\hline & -.18 & -.18 & -.18 & -.11 & -.09 & -.34 & & & \\
\hline & .02 & -.14 & .12 & -.06 & -.04 & -.29 & .94 & .96 & .75 \\
\hline
\end{tabular}

The last column in the table also shows how the odds of assigning short homework to themselves become smaller when parents assign long homework (taking $>30$ minutes to carry out). This could be interpreted as parents "overloading" their children with homework. For instance, the odds of students assigning short homework to themselves is 1.52 times lower as compared to parents who assign no homework $(1.52(=1 / .66)$.

If we consider the impact on students' "long" homework assignment, and we consider parents who give no homework to their students enrolled in rural schools as a reference category, the following picture emerges. The odds become smaller when parents give "short" or "long" homework. For example, these odds are 1.44 smaller $(=1 /(0.91 / 1.31))$ as compared to parents who assign no homework.

The former results suggest that student homework assignment compensates parents' behavior. If the parents already give long homework, the students are less likely to assign homework to themselves. But, when parents give short homework to their children, this increases the likelihood that these students also assign short homework to themselves. The analysis results in this section seem not to be affected by the parents' job level.

\subsection{Homework and mathematics performance}

4.3.1 Does parent assignment of homework affect student mathematics performance level, considering the school urbanization and family SES?

First, the general picture indicates that (1) if parents assign at less short homework to their children, (2) when the job level of the parents increases and (3) the urbanization level of the school increases, also the odds increase of being a high achiever. There are two exceptions: when students are from low job families and are enrolled in rural-urban schools, the odds of being a high achiever becomes very high; and, when the students are from white collar families and are enrolled in rural-urban schools, the odds of being a high achiever decrease. 


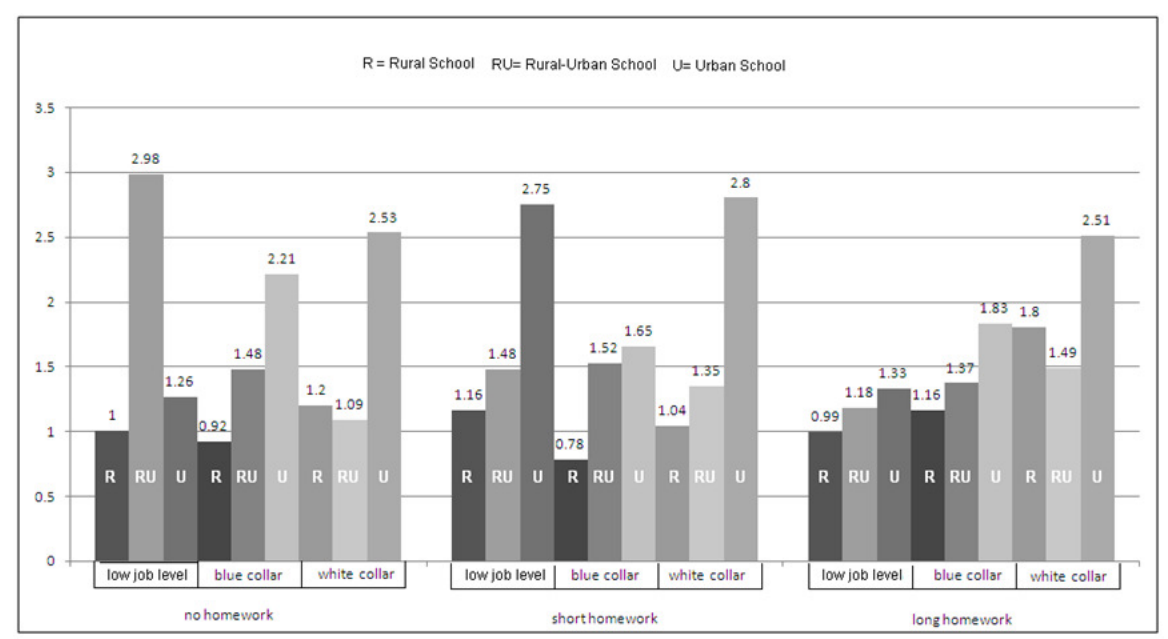

Figure 3. Odds ratios of being a high achiever depending on the level of homework assignment by parents (P) and considering urbanization level of the school's region and parents' job level.

Note: R refers to rural school; RU refers to rural-urban school; U refers to Urban school.

When it comes to the particular impact of parents assigning homework to the students, a particular picture emerges (see Figure 3). Parent homework assignment does not seem to have an impact, especially not for the students in the rural schools. The odds of being a high achiever do not change, whatever the amount of the homework given by the parents.

When the parents' job level is aligned with the urbanization level of the region where the school is located (e.g., parents with a low level job and students are enrolled in a rural school), a U-shaped relationship can be observed in the odds of being a high achiever. In this context, assignment of short homework by the parents will contribute to students' achievement, while no homework or long homework have a small effect.

4.3.2 Does student assignment of homework affect their mathematics performance level considering the school urbanization, family SES and parent's homework involvement?

Figure 4 shows in a transparent way the impact of student homework assignment on achievement levels. When we first focus on students with blue collar parents, the odds of being a high achiever mainly depends on the urbanization level of the school. In the figure, we see how the slope in the odds increases depending on the urbanization level of the school and hardly differs depending on the level of student homework assignment. But, when students have parents with a low level job or a white collar job, the picture becomes different.

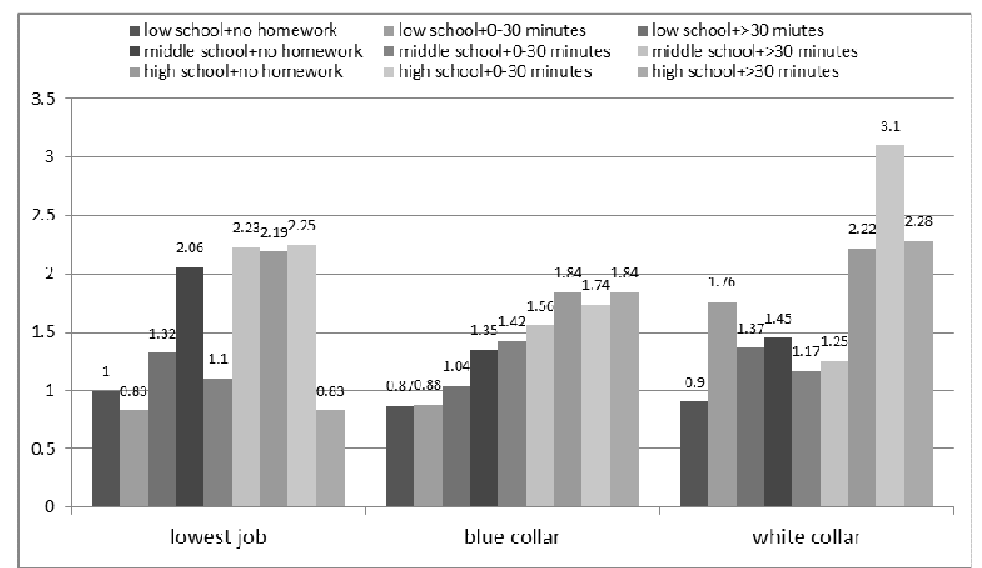

Figure 4. Odds ratios for being a high achiever, considering the level students assign themselves homework, parents' job level and urbanization level of the school.

Note: $\mathrm{N}$ refers to no homework; S refers to short homework; L refers to long homework. 
In general, the odds of being a high achiever are larger in urban schools as compared to schools in rural or urban-rural regions. The odds of being a high achiever in rural schools are larger when the parents have either a low level job or a white collar job level. The impact of the urbanization level of the school's region is obvious when we focus in Figure 4 on the changes in odds of students who don't assign homework to themselves. The odds of being a high achiever are larger in rural-urban and urban schools as compared to the odds in students enrolled in rural schools. In rural schools, the odds for being a high achiever for students with low job level parents, are $1.11(=1 / .9)$ times higher as compared to students with white collar parents. In rural-urban schools, the odds of being a high achiever for students with low level job parents is $1.42(=2.06 / 1.45)$ times higher compared to these odds for students with white collar parents.

A key question is whether the level of homework assignment by students compensates for a weaker context (e.g. rural schools and/or parents with low level jobs)? The results as reflected in Figure 4 show that also students in these less advantageous situations can change the odds of being a high achiever if they assign more homework. But, compared to the students in an advantageous situation (white collar parents and enrolled in urban schools), these extra efforts only become apparent when the latter students don't make efforts and don't assign homework to themselves. In addition, we also observe that students of parent with low level jobs even suffer when they assign long homework to themselves when they are enrolled in schools in rural-urban and in urban regions. For instance, when assigning long homework, the odds of being a high achiever is - for a student from a disadvantaged family and enrolled in an urban school - $1.2(=1 / .83)$ times smaller as compared to the same type of students in a rural school. The results suggest that disadvantaged students in urban schools might suffer from a dual pressure that comes from both their family background and the school context, resulting in lower achievement.

Figure 4 also show that also students from white collar families are affected by contextual variables. These odds of being a high achiever for these students are clearly higher when they are enrolled in urban schools. When they are enrolled in urban schools, they can compensate for this contextual disadvantage by assigning e.g. a sufficient level of homework. As an example, when they assign short homework, the odds that these students are high achievers become $1.96(=1.76 / .9)$ times higher as compared to the reference category.

\section{Discussion, Limitations, and Conclusions}

Previous studies consistently underpinned the linear relationship between socioeconomic status and achievement (Sirin, 2005). This relationship is also confirmed in relation to the impact of homework on achievement (Cooper, Robinson, \& Patall, 2006). The present study differs from earlier research in a number of ways. First, it focused on particular homework situation especially found in Asian context: homework assigned by parents and/or by students. Second, the study differs to the extent that next to family background variables (job level of the parents), we also focused on contextual school variables, such as the urbanization level of the school's region. In general, the findings suggest that students can build on homework to compensate for a disadvantaged situation. Students with parents with lower job levels assign to a higher extent short or long homework to themselves. Secondly, homework assignment seems to mediate in the relationship between parents' job level and academic achievement.

\subsection{Parents' and student's homework assignment as a way to compensate for a disadvantageous situation}

As we can see from the results, parents' job level hardly affects the assignment of homework by the parents. This can be explained by referring to the Chinese context. Based on the Li's Chinese learning model, success is then a matter of time and effort, not inherent ability ( $\mathrm{Li}, 2003)$. For Asian students, homework is considered as investing additional "effort" which is as such a key to academic success (Chen \& Stevenson, 2008; Sue \& Okazaki, 1990). In China, it is believed that effort can compensate for a lack in ability (Hau \& Salili, 1996) and that effort could break the socio-economic barriers affecting disadvantaged families and might be helpful to promote generation and class mobility (Blau \& Ruan, 1990). Thus, engaging in homework is expected to provide 
students - with a disadvantaged family background - with the means to attain a higher occupational level. But, as our results point out, variables at the school level influence parents' behavior. Parents of children enrolled in urban schools seem to be more focused on giving additional homework to their children. This is in line with findings of previous studies that urban school settings foster parents' involvement, more rather than in rural schools (Prater, Bermudez, \& Owens, 1997).

The assignment of homework by students to themselves reflects a more complex pattern and seems to depend on an interaction between the urbanization level of the school's region and parents' job level, next to the interaction between school urbanization level and the extent to which parents assign homework.

The interaction effect of school characteristics level and parents' job level reflects a curvilinear relationship that was also found in earlier studies in the Chinese context (see Cooper et al., 2006; Zhao et al., 2011). This curvilinear relationship is clearly exemplified in Figure 2 that represents the odd ratio of students assigning long homework to themselves. The odds that students with parents with a low job level - in rural and rural urban schools - assign long homework to themselves is clearly larger.

The latter findings are also relevant when discussing the interaction effect of school characteristics and the extent to which parents assign homework. Students that are being assigned short homework also seem to assign short homework to themselves. This reflects the results of previous studies that parents' beliefs about the homework influence students' beliefs about homework (Cooper, Lindsay, Nye, \& Greathouse, 1998). But when parents assign too much homework, students are less likely to assign homework to themselves. The behavior of parents and students seems to be balanced.

\subsection{The impact of homework on academic achievement}

Many variables contribute to academic achievement. The present paper only focused on homework assignment as a catalyst for achievement. Our research results reiterate the recurrent finding in the literature that school level variables and parents' job level play an important role in mathematics performance in Chinese elementary schools. Nevertheless, our results also indicate how parents and students try to compensate for a disadvantageous situation.

The compensatory impact of homework has a small effect. This is in line with earlier studies concluding parents' and students' homework assignments have a limited impact on mathematics achievement (Cooper, Lindsay, Nye, \& Greathouse, 1998). The impact of homework assignment on achievement seems to fluctuate with the interaction patterns in urbanization level of the school and the parents' job level. Only when the homework assigned by the student is long, in families with low job level parents, the odds of being a high achiever become higher. But the head start of students from white collar families is still present. The moment when these students assign homework to themselves, the odds that they are a high achiever clearly become larger. These results re-confirm the results from previous study on the relationship between socioeconomic status and mathematics achievement (Zhao et al., 2012).

In the Chinese context, families and society stress the importance of education (Chao, 1996). Homework has been regarded as a valued strategy to improve the achievement. Although giving too much homework can put too much pressure on students and restricts the improvement of their achievement, homework affects achievement (Lin \& Chen, 1995). That clarifies why in previous studies it is found that even elementary school students spend a lot time on homework (Guo, Liu, \& Zhao, 2006). Although Chinese parents and students seem to believe that hard work - e.g., by assigning homework - will compensate for a disadvantaged situation, our results suggest that this is only true to a limited extent. This implies that educational authorities should be aware of this situation and that additional efforts should be made to compensate for the unfavorable background of groups of students in the school system. The results suggest that the extra efforts of the parents and/or the students themselves might not be sufficient to improve their opportunities for a better future. 


\subsection{Limitations and directions for future research}

The present study provides specific cultural explanations about the impact of homework assignment and academic achievement. Though interesting results could be presented, also some limitations of the study should be considered. Firstly, although this study coveres both students' and parents' homework assignment, it ignores the actual homework completion and its quality. With respect to quality, previous studies reveal that completion and a high quality improve academic achievement to a larger extent as compared to simply giving more homework (Cooper, Lindsay, Nye, \& Greathouse, 1998). A second limitation is that we explore homework assignment behavior, but ignore parents' and students' attitudes towards homework (Trautwein \& Lüdtke, 2009). Our model implies that homework reflects a students' motivation. But this assumption has not been empirically tested. Our results should therefore be approached with cautiousness. Attitudes towards homework can have a different influence on children's motivation and as such affect achievement. Thirdly, we should address the issue of homework and its relationship with achievement in a more comprehensive way. Next to parents' and students' homework, other variables and processes at the student, teacher, and school level should be considered. Especially when we want to focus on compensatory mechanisms to counter the effects of a disadvantaged situation, more comprehensive and culture related issues should be focused upon in the Chinese context.

Acknowledgements: This research was supported by the Project of the National Social Sciences Program Fund, China (The factors which contributing to the immigrated students in China, No. 13CSH072).

\section{References}

Bankston, III. C., \& Caldas, S. J. (1993). Majority African American schools and social Injustice: the influence of De Facto Segregation on Academic Achievement. Social Forces, 75(2), 535-555. http://dx.doi.org/10.1093/sf/75.2.535

Bennett, S., \& Kalish, N. (2006). The case against homework: How homework is hurting our children and what we can do about it. New York: Crown.

Blau, P. M., \& Ruan, D. C. (1990). In-equality of Opportunity in Urban China and America. In A. L. Kalleberg (Ed.), Research in stratification and mobility (Vol. 9). CT: JAI Press.

Bryk, A. S., Holland, P. B., Lee, V. E., \& Carriedo, R. A. (1984). Effective Catholic schools: an exploration. Washington, DC: National Catholic Education Association.

Buell, J. (2004). Closing the book on homework: Enhancing public education and freeing family time. Philadelphia: Temple University Press.

Chao, R. K. (1996). Chinese and European American mothers' beliefs about the role of parenting in children's school success. Journal of Cross Cultural Psychology, 27(4), 403-423. http://dx.doi.org/10.1177/0022022196274002

Chen, C., \& Stevenson, H. W. (2008). Motivation and mathematics achievement: a comparative study of Asian-American, Caucasian-American, and East Asian high school students. Child Development, 66(4), 1215-1234. http://dx.doi.org/10.2307/1131808

Chiu, M. M., \& Zeng, X. H. (2008). Family and motivation effects on mathematics achievement: Analyses of students in 41 countries. Learning and Instruction, 18(4), 321-336. http://dx.doi.org/10.1016/j.learninstruc.2007.06.003

Cooper, H. (1989). Homework. White Plains, NY: Longman. http://dx.doi.org/10.1037/11578-000

Cooper, H., Lindsay, J. J., \& Nye, B. (2000). Homework in the home: how student, family, and parenting-style differences relate to the homework process. Contemporary Educational Psychology, 25(4), 464-487. http://dx.doi.org/10.1006/ceps.1999.1036

Cooper, H., Lindsay, J. J., Nye, B., \& Greathouse, S. (1998). Relationships among attitudes about homework assigned and completed, and student achievement. Journal of Educational Psychology, 90(1), 70-83. http://dx.doi.org/10.1037/0022-0663.90.1.70 
Cooper, H., Robinson, J. C., \& Patall, E. A. (2006). Does homework improve academic achievement? A synthesis of research, 1987-2003. Review of Educational Research, 76(1), 1-62. http://dx.doi.org/10.3102/00346543076001001

Desoete, A., \& Roeyers, H. (2005). Cognitive building blocks in mathematical problem solving in grade 3. British Journal of Educational Psychology, 75, 119-138. http://dx.doi.org/10.1348/000709904X22287

Ebbeck, M. (1996). Parents expectations and child rearing practices in Hong Kong. Early Child Development and Care, 119 (1), 15-25. http://dx.doi.org/10.1080/0300443961190102

Eccles, J. S. (2007). Families, schools, and developing achievement-related motivations and engagement. In J.E. Grusec \& P. D. Hastings (Eds.), Handbook of socialization: Theory and research (pp. 665-691). New York, NY: Guilford Press.

Englund, M. M., Luckner, A. E., Whaley, G. J. L., \& Egeland, B. (2004). Children's achievement in early elementary school: Longitudinal effects of parental involvement, expectations, and quality of assistance. Journal of Educational Psychology, 96(4), 723-730. http://dx.doi.org/10.1037/0022-0663.96.4.723

Fan, X. \& Chen, M. (2001). Parental involvement and students' academic achievement: A meta-analysis. Educational Psychology Review, 13(1), 1-22. http://dx.doi.org/10.1023/A:1009048817385

Gordon, A. \& Wang, Q. (2000). Education in rural areas of China and South Africa: comparative perspectives on policy and educational management. Retrieved from http://unesdoc.unesco.org/images/0012/001218/121853eo.pdf

Grolnick, W. S., \& Ryan, R. M. (1989). Parent styles associated with children's self-regulation and competence in school. Journal of Educational Psychology, 81(2), 143-154. http://dx.doi.org/10.1037/0022-0663.81.2.143

Grolnick, W. S., Benjet, C., Kurowski, C. O., \& Apostoleris, N. H. (1997). Predictors of parent involvement in children's schooling. Journal of Educational Psychology, 89(3), 538-548. http://dx.doi.org/10.1037/0022-0663.89.3.538

Guo, H., Liu, X. M. \& Zhao, J. P. (2006). A survey on students' homework in comment elementary and secondary schools of four areas of China. Journal of Educational Studies [In Chinese], 6(2), 29-39.

Hallam, S. (2004). Homework: the evidence, London: Institute of Education.

Hampden-Thompson, G., \& Johnston, J. S. (2006). Variation in the relationship between nonschool factors and student achievement. Washington, DC: NCES.

Hau, K-T, \& Salili, F. (1996). Prediction of academic performance among Chinese students: effort can compensate for lack of ability. Organizational Behavior and Human Decision Process, 65(2), 83-94. http://dx.doi.org/10.1006/obhd.1996.0008

Ho, E. S., \& Willms, J. D. (1996). Effects of parental involvement on eighth-grade achievement. Sociology of Education, 69(2), 126-141. http://dx.doi.org/10.2307/2112802

Hong, E., \& Milgram, R. M. (2000). Homework: Motivation and learning preference. Westport, CT: Bergin \& Garvey.

Hong, E., Peng, Y., \& Rowell, L. L. (2009). Homework self-regulation: Grade, gender, and achievement-level difference. Learning and Individual Difference, 19, 269-276. http://dx.doi.org/10.1016/j.lindif.2008.11.009

Hoover-Dempsey, K. V., Battiato, A. C., Walker, J. M. T., Reed, R. P., DeJong, J. M., \& Jones, K. P. (2001). Parental involvement in homework, Educational Psychologist, 36(3), 195-209. http://dx.doi.org/10.1207/S15326985EP3603_5

Jeynes, W. H. (2003). A meta-analysis: the effects of parental involvement on minority children's academic achievement. Education and Urban Society, 35(2), 202-218. http://dx.doi.org/10.1177/0013124502239392

Kerbow, D., \& Bernhardt, A. (1993). Parent intervention in the school: The context of minority involvement. In J. Coleman \& B. Schneider (Eds.), Parents, their children, and schools (pp. 115-145). Boulder, CO: Westview.

Lee, V. E., \& Bryk, A. S. (1989). A multilevel model of the social distribution of high school achievement. Sociology of Education, 62(3), 172-192. http://dx.doi.org/10.2307/2112866 
Can parents' homework assigned compensate for disadvantaged students' learning achievement?

Li C. L. (2005a). Cleavage and fragmentation: An empirical analysis of social stratification in contemporary China [In Chinese]. Beijing: Sociology Science Publisher.

Li, C. L. (2005b). Prestige stratification in the contemporary china: Occupational prestige measures and socio-economic index [In Chinese]. Sociological Research, 2, 74-102.

Li, J. (2003). U.S. and Chinese cultural beliefs about learning. Journal of Educational Psychology, 95(2), 258-267. http://dx.doi.org/10.1037/0022-0663.95.2.258

Li, S. Y. (2009). Survey on the students' homework in higher grade in shanghai [In Chinese]. Master thesis in Shanghai normal university.

Lin, J., \& Chen, Q. (1995). Academic pressure and impact on students' development in China. McGill Journal of Education, 30(2), 149-168.

Luan, X. F. (2007). The study of the primary school pupils' homework [In Chinese]. Master Thesis in Northwest Normal University.

Ma, X. (2000).Hierarchical linear modeling of student and school effects on academic achievement. Canadian Journal of Education, 25(1), 41-55. http://dx.doi.org/10.2307/1585867

Maehr, M., \& Nicholls, J. G. (1980). Culture and achievement motivation: a second look. In N. Warren (Ed.), Studies in Cross-cultural Psychology (Vol 2, pp. 221-267). London: Academic Press.

Mclntire, W., Marion, S., \& Quaglia, R. (1990). Rural school counselors: Their communities and schools. The School Counselor, 37(3), 166-172.

Ministry of Education in P. R. China. (MOE). (2001). Mathematics curriculum standards in the phase of full-time compulsory education - Experimental manuscript [In Chinese]. Beijing: Beijing Normal University Publisher.

Muthén, L. K., \& Muthén, B. (1998-2007). Mplus user's guide (5th ed.). Los Angeles, CA: Muthén and Muthén.

National educational commission. (1994). Carry out the educational principle, effectively reduce too heavy homework assignments for primary and secondary school students. Retrieved from http://www.educationalreform.net.cn/article/5.htm

Nunes, T., Bryant, P., Evans, D., Bell, D., Gardner, S., Gardner, A., \& Carraher, J. (2007). The contribution of logical reasoning to the learning of mathematics in primary school. British Journal of Development Psychology, 25(1), 147-166. http://dx.doi.org/10.1348/026151006X153127

Patall, E. A., Cooper, H., \& Robinson, J. C. (2008). Parent involvement in homework: A research synthesis. Review of Educational Research, 78(4), 1039-1101. http://dx.doi.org/10.3102/0034654308325185

Prater, D. L., Bermudez, A. B., \& Owens, E. (1997). Examining parental involvement in rural, urban and suburban schools. Journal of research in rural education, 13(1), 72-75.

Scott-Jones, D. (1984). Family influences on cognitive development and school achievement. In E. Gordon (Ed.), Review of research in education (Vol. 11, pp. 227-258). Washington DC: American Educational Research Association.

Shouse, R. C. (1996). Academic press and sense of community: Conflict, congruence, and implications for student achievement. Social Psychology of Education, 1(1), 47-68. http://dx.doi.org/10.1007/BF02333405

Sirin, S. R. (2005). Socioeconomic status and academic achievement: A meta-analytic review of research. Review of Educational Research, 75(3), 417-453. http://dx.doi.org/10.3102/00346543075003417

Sue, S., \& Okazaki, S. (1990). Asian-American educational achievements: a phenomenon in search of an explanation. American Psychologist, 45(8), 913-920. http://dx.doi.org/10.1037/0003-066X.45.8.913

Trautwein, U. (2007). The homework-achievement relation reconsidered: Differentiating homework time, homework frequency, and homework effort. Learning and Instruction, 17(3), 372-388. http://dx.doi.org/10.1016/j.learninstruc.2007.02.009

Trautwein, U., \& Lüdtke, O. (2007). Students' self-reported effort and time on homework in six school subjects: Between-student differences and within student variation. Journal of Educational Psychology, 99(2), 432-444. http://dx.doi.org/10.1037/0022-0663.99.2.432

Trautwein, U., \& Lüdtke, O. (2009). Predicting homework motivation and homework effort in six school subjects: the role of person and family characteristics, classroom factors, and school track. Learning 
and Instruction, 19(3), 243-258. http://dx.doi.org/10.1016/j.learninstruc.2008.05.001

Vermunt, J.K. (1997). LEM: A general program for the analysis of categorical data. Department of Methodology and Statistics, Tilburg University.

Wang, T. (2004). Present situation and development of rural basic education in northwest China. Distance Education in China, 3(32), 64-67.

Warton, P. M. (1997). Learning about responsibility: Lessons from homework. British Journal of Educational Psychology, 67(2), 213-221. http://dx.doi.org/10.1111/j.2044-8279.1997.tb01238.x

White, K. R. (1982). The relation between socioeconomic status and academic achievement. Psychological Bulletin, 91(3), 461-481. http://dx.doi.org/10.1037/0033-2909.91.3.461

Xu, J., \& Corno, L. (1998). Case studies of families doing third-grade homework. Teachers College Record, $100(2), 402-436$.

Zhao, N., Valcke, M., Desoete, A., \& Verhaeghe, J. (2012). The quadratic relationship between socioeconomic status and learning performance in China by multilevel analysis: Implications for policies to foster education equity. International Journal of Educational Development, 32(3), 412-422. http://dx.doi.org/10.1016/j.ijedudev.2011.08.004

Zhao, N., Valcke, M., Desoete, A., Verhaeghe, J., \& Xu, K. (2011). A multilevel analysis on predicting mathematics performance in Chinese primary schools: Implications for practice. Asia-Pacific Education Researcher, 20(3), 503-520.

Zimmerman, B. J., \& Kitsantas, A. (2005). Students' perceived responsibility and completion of homework: The role of self-regulatory beliefs and processes. Contemporary Educational Psychology, 30(4), 397-417. http://dx.doi.org/10.1016/j.cedpsych.2005.05.003

Zimmerman, W., \& Cunningham, S., (Eds.). (1991). Visualization in teaching and learning mathematics. Washington, DC: American Mathematical Association. 